\title{
LA BIBLIOTECA DEL SEMINARIO METROPOLITANO SAN ATÓN DE BADAJOZ
}

\author{
POR \\ Ma Guadalupe Pérez Ortiz \\ Directora Biblioteca Seminario Metropolitano San Atón \\ FRANCISCO GoNZÁLEZ LOZANO \\ Profesor del Instituto Superior de Ciencias Religiosas Santa María de Guadalupe \\ y Rector Seminario Metropolitano de San Atón
}

Según consta en el Libro de Fundación del Seminario, ${ }^{1}$ el tres de mayo de mil seiscientos sesenta y cuatro, se nombraron los primeros colegiales, se les impusieron las becas y, junto al Rector, entraron en el que será el «Seminario Conciliar de San Atón». Han pasado casi trescientos cincuenta años de este singular acontecimiento tanto para la Iglesia como para la cultura extremeña. Durante el año 2014, el Seminario Metropolitano San Atón conmemorará este aniversario fundacional. Nos mueve a ello la herencia educativa recibida y el deseo de resaltar su impronta en la historia eclesiástica y cultural extremeña.

Al volver la mirada atrás, podremos hacer un recorrido histórico para hacer homenaje a la función formativa que esta institución eclesial ha ejercido para el servicio no sólo de la Iglesia, sino de la educación extremeña. Si bien es cierto que la misión fundamental de los seminarios estaba orientada a la preparación integral de los sacerdotes para el servicio de la Iglesia, no es menos indiscutible que por sus aulas han pasado insignes personajes de la cultura general y que han dejado su impronta en la historia de Extremadura.

La influencia en el devenir histórico y cultural extremeño del Seminario ha sido de capital importancia; miles de niños y jóvenes, desde hace casi cuatro siglos, han forjado su personalidad y han aportado su maduración al contexto, - pasado,

\footnotetext{
${ }^{1}$ Libro de Fundación del Seminario San Atón, fol. 12.
} 
presente y futuro - sociocultural y religioso en el que se han insertado, bien como sacerdotes, bien como hombres al servicio de la sociedad.

La formación en valores humanos que sustenta la finalidad del Seminario, la preparación académica que exige la realidad a la que debe servir el sacerdote y la orientación espiritual que guía a los que reciben educación en este centro, son los pilares básicos en los que se ha sostenido tan insigne institución.

Transcurrió un siglo desde que el Concilio de Trento, en 1563, ordenara la erección de los seminarios y el obispo fray Jerónimo Rodríguez Valderas nombrara al primer Rector y se impusieran las becas a los dos primeros colegiales. Las circunstancias eclesiales y económicas fueron impedimentos claves en el retraso del mandato conciliar. Sin embargo, desde 1664 hasta nuestros días, el Seminario San Atón ha cumplido con creces su misión.

Son muchas las herramientas pedagógicas utilizadas a lo largo de los años en la formación de los futuros sacerdotes, pero entre ellas destacamos la Biblioteca como medio fundamental de la preparación intelectual y humanística de los seminaristas. Hoy queremos destacar su vital importancia, tanto por sus fondos históricos como por las perspectivas de investigación que ofrece.

La primitiva «librería» del Seminario, que nacía a la par del mismo, ofrecía sustento científico a la preparación académica de los seminaristas. Y aunque fueron pocos los recursos destinados a la misma, debido a las carencias económicas, años más tarde el obispo Solís y Grajera quiso reflejar en las constituciones para el Seminario el valor y sentido de la Biblioteca como medio formativo, dotándola de normativa y de recursos económicos propios.

El tesoro bibliográfico que custodia es incalculable, aunque puede vislumbrarse en la enorme variedad de materias que recoge y en el número significativo de libros que conserva (43.500 volúmenes y unos 100 títulos de revistas especializadas en diversas ramas del saber, de las que algo más de la mitad se mantienen actualmente en activo).

Merecen un homenaje el Seminario Metropolitano San Atón, por su aportación al patrimonio cultural extremeño, y su Biblioteca como fuente de sabiduría $\mathrm{y}$ herramienta pedagógica formativa en esta ardua tarea.

La Biblioteca del Seminario San Atón ha sido a lo largo de su existencia un recurso esencial en la formación del clero pacense y además, en un momento de la historia, fue la única biblioteca pública de la ciudad de Badajoz, que en las postrimerías del siglo XVIII carecía de ella. Ha sabido conservar a lo largo de su dilatada existencia un importantísimo patrimonio bibliográfico que ha ido ampliando y consolidando en el tiempo. En la actualidad es una de las más importante bibliotecas eclesiásticas de la región y no es superada en fondos clásicos por ninguna otra extremeña de titularidad civil.

Hispania Sacra, LXVI

133, enero-junio 2014, 373-387, ISSN: 0018-215X, doi: 10.3989/hs.2013.057 
Los autores que se han ocupado del estudio del Seminario Metropolitano de San Atón en el pasado siglo xx no han podido menos que dedicar algunas páginas de sus interesantes trabajos a la Biblioteca. Así lo hicieron: Antonio del Solar y Taboada, Pedro Rubio Merino y Mateo Blanco Cotano. ${ }^{2}$ De igual modo, lo siguen haciendo otros autores que por medio de sus aportaciones dan a conocer este gran tesoro patrimonial y bibliográfico ${ }^{3}$ con el que el Seminario Metropolitano de San Atón cuenta.

Nos disponemos, a partir de este momento a presentar un pilar esencial dentro de la estructura del Seminario Metropolitano San Atón: su biblioteca. Para ello debemos, al menos someramente, contextualizar dos piezas importantes: $\mathrm{el}$ seminario pacense y como consecuencia directa de ello, el nacimiento a nivel general de los seminarios, tras las ya lejanas disposiciones tridentinas.

Sin llevar a término, al menos un breve análisis del nacimiento de los seminarios españoles y de forma específica del seminario de Badajoz, no podremos entender el significado que la biblioteca tiene dentro de la estructura de la entidad a la que pertenece.

\section{NACIMIENTO DE LOS SEMINARIOS EN EL MARCO TRIDENTINO}

La pregunta sobre el nacimiento de una nueva institución orientada a la formación de los clérigos nos lleva a la situación de la Iglesia católica en un periodo de confusión doctrinal provocada por las teorías de Lutero, Calvino y Zwinglio. La teología católica comenzaba a resquebrajarse, por lo que fue necesario un impulso a la formación sacerdotal y una reforma que pusiera en firme los dogmas católicos.

Así pues, los seminarios nacieron a raíz del Concilio de Trento (1545-1563) como centros para atender la formación del clero que en el siglo XVI era un tanto

${ }^{2}$ Solar y Taboada, A. 1945. El Seminario de San Atón de Badajoz: 85-89. Badajoz; Rubio Merino, P. 1964. El Seminario de San Atón de Badajoz (1664-1994): 304-310. Madrid: Monte de Piedad y Caja Genera del Ahorros de Badajoz; Blanco Cotano, M. 1998. El primer centro universitario de Extremadura. Badajoz 1793. Historia pedagógica del Seminario de San Atón: 218-222. Cáceres: Universidad de Extremadura.

${ }^{3}$ Tejada Vizuete, F. y Pérez Ortiz, Ma G. 2011. «La Biblioteca del Seminario Metropolitano de San Atón: origen y desarrollo». Catálogo de la Exposición en honor a san Juan de Ribera: mayo-junio de 2011; Pérez Ortiz, M ${ }^{a}$ G. «La biblioteca del Seminario Metropolitano de San Atón de Badajoz: la mejor colección religiosa de Extremadura». Mi Biblioteca VIII: 105-112; Pérez Ortiz, Mª G. y Tejada Vizuete, F. «La Biblioteca del Seminario Metropolitano San Atón de Badajoz: un presente con mucha historia». Vitela X: 4-7; Vizuete, F. y Pérez Ortiz, Mª G. «La biblioteca del Seminario Metropolitano de San Atón. Libros del siglo xvi impresos en España, Lyon, París, Amberes, Italia, Alemania y Portugal», Pax et Emerita. Revista de Teología y Humanidades de la Archidiócesis de Mérida-Badajoz. III-VII. 
escasa. En concreto, en la sesión XXIII del Concilio, que se desarrolló desde el 15 de julio de 1563 al 11 de noviembre de 1563 , se aborda, junto con la doctrina sobre el Sacramento del Orden, aprobada bajo el Decreto sobre la Reforma, la creación de seminarios para los clérigos y se dispone que las catedrales fueran las que se encargaran de la fundación y consolidación de los mismos.

«Establece el santo Concilio que todas las catedrales, metropolitanas e Iglesias mayores, tengan obligación de mantener y educar religiosamente, e instruir en la disciplina eclesiástica, según las posibilidades y extensión de las diócesis, cierto número de jóvenes de la misma ciudad y diócesis, o, a no haberlos en ésta, de la misma provincia, en una colegio situado cerca de las mismas Iglesia, o en otro lugar oportuno, a elección del obispo...

Cuide el obispo que asistan todos los días al sacrificio de la Misa, que confiesen a los menos una vez al mes, que reciban, a juicio del confesor, el Cuerpo de nuestro Señor Jesucristo, y que sirvan en la catedral y en otras Iglesias del pueblo los días festivos.

El obispo... arreglará, según el Espíritu Santo le iluminare, todo lo dicho, y todo cuanto sea oportuno y necesario, velando en sus frecuentes visitas de que siempre se guarde»... (ses. 23 , can. 18 de reforma). ${ }^{4}$

Antes de la celebración del Concilio de Trento, la formación sacerdotal en lo que concierne al clero secular, no existía como tal y la ordenación de nuevos sacerdotes estaba supeditada a juegos e intereses políticos durante el Medioevo y casi reservada a las clases más poderosas. Las reflexiones del Concilio de Trento nos acercan a un clero que se presentaba frágil intelectualmente. De esta manera se decreta la creación y la obligatoriedad de los seminarios sacerdotales en las diócesis, lo cual es confirmado por el Papa Pío IV. ${ }^{5}$ En los textos de reforma tridentina se urge a la santidad, acción pastoral, predicación de la palabra, dando suma importancia a la formación sacerdotal previa a la ordenación del candidato. El Catecismo de Trento recoge esta doctrina detalladamente. ${ }^{6}$

Algunos puntos a destacar del texto tridentino sobre los seminarios, extraídos del citado Catecismo son:

Se exige la erección del Seminario en cada diócesis, aunque no se obliga a los clérigos a formarse en ellos. Esta última circunstancia creará algunas dificultades hasta el inicio del siglo xx.; La formación impartida en el Seminario debe ser intelectual y moral, cuidando de la selección previa de los candidatos.

${ }^{4}$ De reformatione. Sesión 23, cap. 4, can. 4. Cfr. Concilium Tridentinum, Diariorum, Actorum, Epistularum, Tractatuum nova Collectio IX, 1901: 628-630.

${ }^{5}$ Rops, D. 1970. Historia de la Iglesia: 104-ss. Madrid: Luis de Caralt.

${ }^{6}$ Martín, P. 1956. Catecismo Romano. Madrid: Biblioteca de Autores Cristianos. 
No sólo hay que ser pulcros en la selección de los candidatos, también en la de sus formadores dado que condicionaran directamente la formación de los seminaristas.

Se provee a la sustentación económica de la Institución.

Se otorga suma importancia a la intervención del obispo en la marcha del Seminario, puesto que se trata de la formación de su propio presbiterio. Debe cuidar de la selección de los formadores, del buen ambiente del Seminario, de la formación espiritual e intelectual, de la relación pastoral con la catedral, etc.

Justo un año después de la celebración del Concilio de Trento se erige la Congregación del Concilio, que tendría el cometido de vigilar la aplicación de los decretos tridentinos, especialmente en todo lo referente a la reforma de las diócesis y de la vida clerical. Los obispos tendrían que dar cuenta periódicamente de la aplicación de estas disposiciones.

Durante la segunda mitad del siglo XVI y hasta finales del siglo XVII, la aplicación del decreto conciliar fue urgida por Sínodos particulares, obispos y sacerdotes. Fueron éstos quienes instaron más a hacer realidad la institución y la orientación de los Seminarios: San Pío V, San Carlos Borromeo, San Gregorio Barbarigo, San Juan de Ribera, San Juan de Avila... ${ }^{7}$ Durante el siglo XVII, en Francia fueron las grandes figuras sacerdotales quienes aplicaron las disposiciones tridentinas: San Vicente de Paúl, Pedro de Bérulle, Adrián Bourdoise, Santiago Olier, San Juan Eudes... La escuela francesa abrió nuevos cauces a la formación sacerdotal en los seminarios, especialmente en lo referente al seguimiento espiritual e integral de los candidatos. ${ }^{8}$ Además observamos actuaciones similares en países como Italia, España ${ }^{9}$ o Centroeuropa que se prolongaron en el tiempo; nótese también la influencia del colegio germánico como experiencia notable previa a la fundación de los seminarios. ${ }^{10}$

${ }^{7}$ San Juan de Ávila, cuyo nombramiento como Doctor de la Iglesia se celebró en Roma el 7 de octubre de 2012, es considerado como insigne precursor de los Seminarios conciliares. En sus Advertencias podemos leer: «En la educación de los que han de estar en el Seminario va lo principal de este negocio; y por esto es necesario tenga el cargo de regirlos una misma persona (...), de tal manera que salgan maestros verdaderos de las almas redimidas con la Sangre del Señor».

${ }^{8}$ Esquerda Bifet, Juan. 1991. Teología de la espiritualidad sacerdotal: 379-381. Madrid: Biblioteca de Autores Cristianos.

9 Vergara Ciordia, J. 1996. Historia de la acción educadora de la Iglesia en España (I): 499526. Madrid: Biblioteca de Autores Cristianos; Martín, Francisco. 1995. «Los seminarios, la formación del clero y de los religiosos», en Historia de la acción educadora de la Iglesia en España. Madrid: Biblioteca de Autores Cristianos.

10 Vergara Ciordia, J. 2004. Historia y pedagogía del Seminario conciliar en Hispanoamérica (1563-1800): 38-39. Madrid: Dykinson. 
AproXimaCión a LA HISTORIA DEl SEMINARIO METROPOLITANo SAN Atón DE BADAJOZ

El tiempo constata que la creación de los seminarios no fue un hecho inmediato a la promulgación de los decretos tridentinos, sino que se fue dilatando en el tiempo, en algunos casos en exceso. Una de las razones por las que se retrasó el inicio de estas instituciones fue la coexistencia con Colegios y Universidades en los cuales se preparaban muchos clérigos.

La Universidad española gozaba de gran prestigio y entorno a ella surgieron estos centros universitarios que hicieron las veces de seminarios. ${ }^{11}$ Junto a la existencia de estos centros formativos, otras razones que impidieron la inmediata fundación de los seminarios fueron la pobreza de las diócesis y la resistencia de algunos cabildos catedralicios que, previamente, habían llevado la dirección de las escuelas catedralicias que antaño cumplieron la misión de la formación de futuros sacerdotes.

Algo similar podemos observar en la ciudad de Badajoz. Por ello, el rey Felipe II tuvo que recordar a nuestro cabildo, entre otros, en febrero de 1594, que habían pasado más de treinta años desde la celebración del Concilio de Trento y que no se había hecho nada al respecto para la constitución del seminario en nuestra ciudad. Veamos literalmente sus palabras:

«avía mas de treinta / años que el concilio se avía publicado y esta obra..., tan neçesaria y conveniente / para todo el Reyno por la utilidad que resultaría de que los niños se criasen en / buena doctrina y costumbres y letras, no se avía executado ni cumplido», por lo que ruega y encarga a la corporación capitular «que dentro de veinte días primeros siguientes después / que os fuera mostrada - la carta - enviéis ante los del nuestro consejo relación, en manera que / haga fee, si en esse obispado se a hecho el dicho seminario por la orden que por el / sanctoconçilio se dispone y quánto a que se hiço y qué renta se le applicó». ${ }^{12}$

La escasez de beneficios y rentas obligaron al Cabildo a dilatar en el tiempo la creación de nuestro seminario. Sabido era por nuestros canónigos que debían cumplir con los mandatos tridentinos sin más dilación, pero muy a su pesar no podían hacer nada al respecto porque no contaban con fondos suficientes para su ejecución y mantenimiento.

La exigencia conciliar había encontrado eco en alguno de los prebendados de la catedral de Badajoz. Este hecho lo pone de manifiesto el testamento del canónigo don Rodrigo Dosma Delgado. En dicho testamento, otorgado el 8 de mayo de 1588 , sus bienes quedaban vinculados a favor de la descendencia que

${ }^{11}$ Blanco Cotano, M. 1998: 26; Fernández Conde, M. 1948. España y los seminarios tridentinos: 21-22. Madrid: CSIC.

${ }^{12}$ A.C.B. Cartas Reales, Tomo $1^{\circ}, \mathrm{n}^{\mathrm{o}} 20$.

Hispania Sacra, LXVI

133, enero-junio 2014, 373-387, ISSN: 0018-215X, doi: 10.3989/hs.2013.057 
tuviera su hermano, siguiendo como beneficiarios los sucesores de la misma; pero, faltando tal descendencia y sucesores, las dos terceras partes de tales bienes pasarían al que fuera «seminario que se erija en las casas grandes de mi morada» y si tal seminario hubiera sido erigido antes de que tales bienes quedaran desvinculados era voluntad de nuestro canónigo que, producido este hecho, pasase de inmediato a sus casas. ${ }^{13}$

Al principio existieron problemas con los herederos directos del canónigo, que tuvo que refrendar el obispo don Jerónimo Rodríguez de Valderas (16621668), consiguiendo que el seminario se instaurara en la casa del fallecido canónigo en el año 1664 y estableciendo que fuera primer rector del mismo, el licenciado don Juan López Jaramillo, al que le tocó la ardua tarea de poner en marcha una institución desconocida pero de la que se esperaba un funcionamiento rápido y eficaz.

Permaneció el seminario en estas instalaciones, próximas a nuestra catedral, durante algún tiempo. Posteriormente, y debido a las necesidades de espacio, que cada vez eran más patentes, y gracias las negociaciones del obispo don Amador Merino Malaguilla (1730-1755) se compran unas casas que pertenecían por aquel entonces al conde don Juan Manuel de Villena y otros terrenos del Marqués de Gramosa y después de unas profusas obras se traslada el seminario a la plaza de Minayo, el 26 de octubre de 1754, entonces Campo de San Francisco. En este momento es rector del seminario don José González Vaca.

El paso del tiempo y las nuevas circunstancias a las que el seminario tuvo que ir adaptándose, obligaron a plantearse que las dependencias que estaba ocupando hasta el momento no eran las más idóneas, en medio del bullicio de una ciudad que iba creciendo, para la formación de los seminaristas. Por ello, el entonces obispo don Ramón Pérez Rodríguez se decidió a buscar unas nuevas instalaciones alejadas del centro de Badajoz, pensado que así los seminaristas encontrarían unas mejores condiciones para su desarrollo espiritual. Una vez que solventó los trámites legales que fueron surgiendo, el obispo y el cabildo pacense adquirieron una amplia huerta en la Cañada de Sancha Brava y comenzaron la construcción del nuevo edificio.

Tras las obras, en las navidades del año 1927, se sitúa el seminario de Badajoz en este nuevo edificio en el que se encuentra actualmente. A fecha de hoy es rector del mismo don Francisco González Lozano.

\footnotetext{
${ }^{13}$ Cfr. el Prólogo de don Vicente Barrantes a su edición de los Discursos Patrios..., Badajoz, 1870, 47-48.
} 


\section{Edificio del seminario en una etapa anterior}

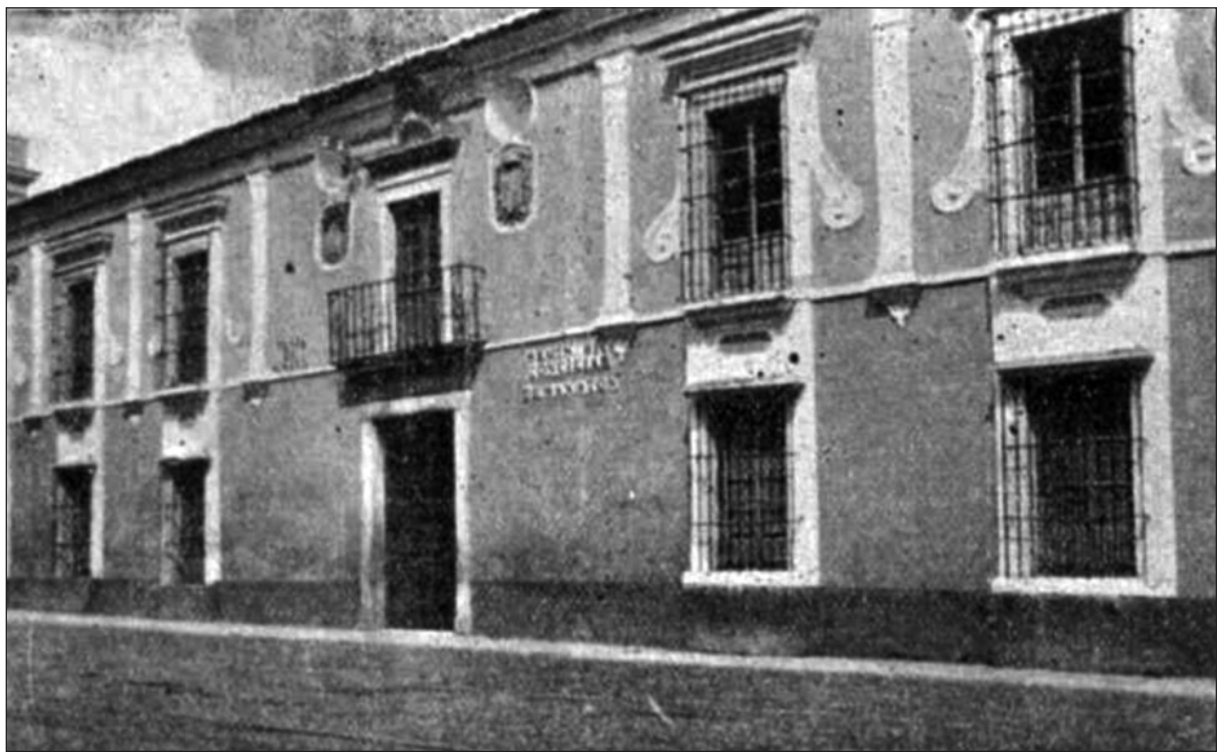

Edificio en la actualidad

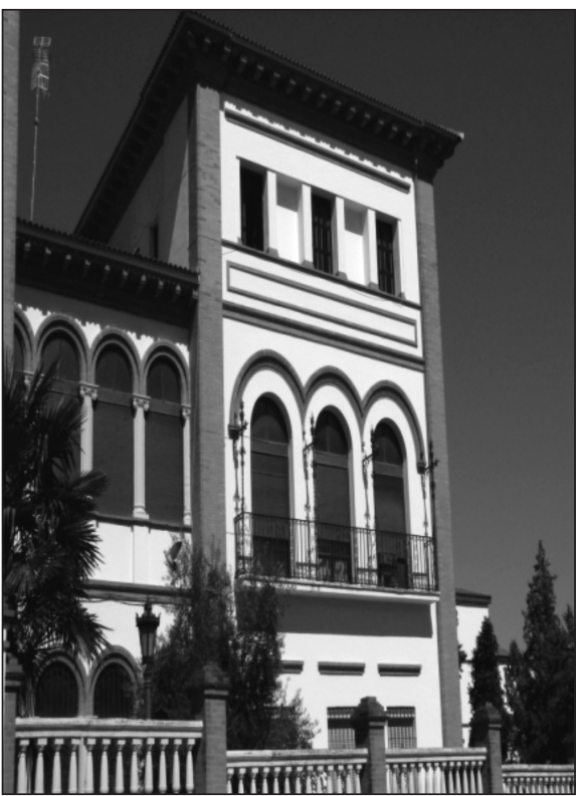

LA BIBLIOTECA DEL SEMINARIO METROPOLITANO SAN ATÓN

«Hemos determinado ceder como en efecto, hemos cedido ara ello los libros y obras mas selectas de nuestra Librería propia y hecho trasladar a dicho Seminario estas, y las que nos han parecido más útiles y convenientes de los libros que se hallan en nuestro Palacio Episcopal...».

Estas palabras fueron formuladas por el obispo Solís y Gragera, al constituir oficialmente la Biblioteca del Seminario de Badajoz, a finales del 1786. Sin embargo, la historia demuestra que un siglo antes ya existía una «librería» que tenía el papel de biblioteca. Por tanto, el origen de la biblioteca del Seminario debemos situarlo coetáneo a la fundación de la institución, en el año

Hispania Sacra, LXVI

133, enero-junio 2014, 373-387, ISSN: 0018-215X, doi: 10.3989/hs.2013.057 
1664, en la llamada «librería del Seminario». Ésta, en un principio se constituía de un pequeño grupo de textos bíblicos, iba aumentando con las condonaciones que diversas instituciones y fieles entregaban y con los 60 reales que los alumnos del seminario pagaban al ingresar. Este capital fue destinado, en parte, a la compra de obras relacionadas con las enseñanzas que se impartían en el centro.

El obispo don Alonso Solís y Gragera (1783-1797) trabajó incesantemente por el buen funcionamiento del seminario pacense. Dos son las principales muestras de su incesante empeño: la creación de unas constituciones para la institución y la puesta en funcionamiento de una biblioteca a la imagen y semejanza de un centro moderno, como ya sucedía en otras diócesis españolas y muy especialmente en Francia e Italia.

La biblioteca se consideró un objetivo primordial del Obispo, que dedica íntegramente el capítulo XXI de sus Constituciones Generales (1784). Es, por tanto el primer documento impreso que recoge punto por punto los elementos constitutivos de la misma, puesto que, aunque sus Constituciones no son las primeras, sí son las únicas, en las que se hacía alusión directa a la biblioteca.

Además de las Constituciones, otro hecho que permite hablar, a partir de este momento, de la existencia de una biblioteca en el Seminario, fue la incorporación a la primitiva «Librería» de los fondos del extinguido Colegio de la Compañía de Jesús de Badajoz y las catorce cargas de libros que se trajeron del Colegio de Jesuitas de Higuera la Real. ${ }^{14}$

Sabido es el importantísimo papel que los Jesuitas desempeñaron, hasta su extinción, en el desarrollo y extensión de la cultura, muy especialmente en los ámbitos relacionados con la educación y la pedagogía. De ahí la riqueza que en sus bibliotecas se custodiaba. Para el Seminario, que hasta el momento contaba con unos fondos mayoritariamente adscritos a las ciencias religiosas, supuso la incorporación de libros de otras ramas del saber: medicina, botánica, física, farmacopea, matemáticas, astronomía, etc. Muchos de éstos están hoy a disposición de los investigadores.

La Biblioteca del Seminario de Badajoz fue primera biblioteca pública de Badajoz, como prueban los estudios de Solar y Taboada, ${ }^{15}$ Rubio Merino ${ }^{16}$ y los más actuales de Blanco Cotano. ${ }^{17}$ El 9 de diciembre de 1786 el obispo Solís y Gragera y el Cabildo catedralicio firmaban un edicto de consolidación para

${ }^{14}$ Libro de contabilidad del Seminario Metropolitano San Atón (1783-1789), fol. 123 en Archivo del Seminario.

${ }^{15}$ Solar y Taboada, A. 1945: 85-89.

${ }^{16}$ Rubio Merino, P. 1964: 304-310.

${ }^{17}$ Blanco Cotano, M. 1998: 218-222. 
la Biblioteca. Este documento, basado en la anterior Constitución de $1784,{ }^{18}$ tenía la función de reafirmarla. Mucho más importante fue, en este momento, la apertura de la Biblioteca al público, convirtiéndola en la primera con carácter público de la ciudad, que, en las postrimerías del siglo xvIII aún carecía de ella.

Solís y Gragera muestra su «ánimo de establecer en el Seminario una biblioteca, como estaba previsto en la Real Orden de 17 de febrero de $1771 »,{ }^{19}$ añadiendo que, «hasta que pueda disponer de mayores arbitrios que le permitan enriquecer y aumentar la biblioteca, ha determinado ceder los libros y obras más selectas de su biblioteca personal y trasladar al seminario las obras que le habían parecido más útiles sitas en el Palacio Episcopal». Se puede deducir, por tanto, la existencia de otra biblioteca eclesiástica en las dependencias episcopales.

Además, establece diversas disposiciones para su buen funcionamiento. Fue el primer reglamento con el que contó la biblioteca del Seminario. En él se establece, entre otras disposiciones, que: el préstamo de libros es restringido, sólo se permite a los profesores y estudiantes que residan en el Seminario; la desaparición de un libro era considerada una falta grave; el préstamo era de tres días y para poder ser efectuado los usuarios debían rellenar una ficha en la que además de sus datos personales indicaban el uso que se le iba a dar al libro; se confecciona un índice alfabético de autores; al frente de la biblioteca coloca como responsable a un catedrático del Seminario que será el único encargado y responsable de la institución.

Cuando inicia, en 1786, su camino, como centro público, la Biblioteca del Seminario contaba con un total de 821 títulos, que superaban los 2000 volúmenes. En los años siguientes, el fondo llega casi a duplicarse. Esta situación es debida, en gran medida, a las aportaciones provenientes de bibliotecas de los colegios jesuitas extinguidos y a las múltiples donaciones, entre las que destacan las de los obispos don Amador Merino y Malaguilla (1730-1755) y don Alonso Solís y Grajera (1783-1797).

De esta etapa es también el Catálogo Fundacional de la Biblioteca, conservado hoy en sus instalaciones. Está forrado en pergamino y consta de un total de 25 hojas. A parte del volumen de libros inventariados, permite conocer el sistema de catalogación empleado en los siglos XVII-XVIII. Los libros se encontraban clasificados alfabéticamente por autores, número de volúmenes, pie de imprenta y fecha de edición.

\footnotetext{
${ }^{18}$ Ibídem: 401-436.

${ }^{19}$ Se refiere a la Real Orden de Carlos III en la que se disponía que en todos los seminarios existiera biblioteca pública.

Hispania Sacra, LXVI

133, enero-junio 2014, 373-387, ISSN: 0018-215X, doi: 10.3989/hs.2013.057
} 
Se registran un gran número de ejemplares de la Biblia, comentarios de las Sagradas Escrituras, obras de Teología Dogmática, Escolástica y Moral, de Filosofía, varios ejemplares de Historia de la Iglesia y de Historia Profana y otras,incluidas bajo el título de «asuntos varios» y que eran, en gran medida, manuales de apoyo a la docencia.

Conformada la Biblioteca, pronto llegó el reconocimiento del Seminario como Centro Universitario, dependiente de la Universidad de Salamanca, por Real Cédula de Carlos IV, de 17 de agosto de 1793. Se establecieron cuatro facultades: Arte, Teología Escolástica y Moral, Derecho Civil y Derecho Canónico.

\section{LA BIBLIOTECA DEL SEMINARIO EN LOS SIGLOS XIX Y XX}

En 1797, al finalizar el mandato de don Alonso Solís y Gragera se cierra la etapa más gloriosa de la historia antigua de la Biblioteca. Cinco años más tarde, en 1802, de la mano del que llegó a ser arzobispo de la diócesis, don Mateo Delgado y Moreno (1802-1841), fue nuevamente foco de preocupación e interés.

En el año 1808, el ejército francés ocupó Badajoz. Este hecho supuso un retroceso en el funcionamiento del Seminario y, en particular, en el de su Biblioteca. Muchos libros fueron robados, otros desaparecieron, algunos se quemaron, perdiéndose para siempre obras de singular relevancia para la historia de la Iglesia y de la cultura en general. Los que tuvieron mejor fortuna permanecieron en poder de las autoridades militares hasta el año 1814, fecha en que fueron recuperados y devueltos a nuestro Seminario.

El primer intento de recuperación de la Biblioteca se da de la mano del don Mateo Delgado y Moreno en el año 1818. Tras la guerra se ordena, por clases y estantes, la documentación conservada. En 1819 se realiza un nuevo catálogo, también conservado en la actualidad, que registra las pérdidas bibliográficas ocasionadas por la guerra. Hay cerca de 1600 obras. Eso supone que desaparecieron para siempre alrededor de mil títulos, de todas las temáticas, pero muy especialmente de teología.

Terminada la guerra y en el transcurso de los siglos XIX y XX, la Biblioteca fue recibiendo múltiples donaciones que sirvieron para aumentar su debilitado patrimonio. Destacan, en primer lugar, obras incautadas a los conventos masculinos de la ciudad de Badajoz durante las desamortizaciones ${ }^{20}$ y, la donación del obispo

\footnotetext{
${ }^{20}$ Representaron un volumen escasamente significativo puesto que la gran mayoría de los títulos incautados fueron destinados a la Biblioteca Pública de Badajoz y a la Diputación Provincial de Badajoz.
} 
don Félix Soto Mancera (1904-1910), por su cantidad y por la calidad de las obras. Para conocer la importancia de la documentación entregada por este obispo, basta mencionar que, gran parte de los incunables y de los ejemplares de mayor valor bibliográfico con los que la Biblioteca cuenta, fueron donados por él.

En el índice general de la donación, conservado en la Biblioteca, se registra un total de 1.466 títulos distribuidos de la siguiente manera:

Filosofía general (ética, política, historia, etc.): 112 títulos.

Sagrada Escritura: 46 títulos.

Teología dogmática: 115 títulos.

Teología moral: 41 títulos.

Santos Padres: 14 títulos.

Teología pastoral: 41 títulos.

Liturgia: 40 títulos.

Derecho canónico: 110 títulos.

Derecho civil: 56 títulos.

Oratoria Sagrada: 77 títulos.

Mística y ascética: 186 títulos.

Controversia: 16 títulos.

Apologética: 41 títulos.

Historia eclesiástica: 83 títulos.

Disciplina eclesiástica: 147 títulos.

Ciencias exactas y naturales: 10 títulos.

Historia de España: 34 títulos.

Literatura: 96 títulos.

Variedades (incluye revistas y folletos): 201.

No todos los títulos llegan a nuestros días, ya que, según el registro automatizado, en elaboración, los ejemplares que ostentan el ex libris acreditativo de pertenecer al legado de don Félix Soto Mancera, sólo alcanza la cifra de 668.

Hubo donaciones de don Aquilino Camacho Macías (Derecho e Historia); don José María Robles Febré (Literatura), don José García (Sagrada Escritura) y don Tomás Fernández Tamayo (Filosofía) y un nutrido conjunto de obras, de variada índole, donadas por el arzobispo don Antonio Montero.

\section{LA BIBLIOTECA DEL SEMINARIO: PRESENTE Y FUTURO}

¿Cómo es hoy la Biblioteca? Desglosaremos aquellos aspectos que permiten conocer su funcionamiento y estructura.

Desde 1927, la Biblioteca se sitúa en el Seminario Metropolitano de San Atón. Se trata de un edificio amplio. Sus fondos se distribuyen en tres plantas, 
con librerías adosadas a sus muros y una plataforma central, que, hace algunos años, permitió aumentar su capacidad. El fondo ha crecido considerablemente en los últimos tiempos creando problemas de espacio. En el año 2012, se ha ampliado con una sala contigua.

En líneas generales podemos afirmar que el fondo de la biblioteca pertenece, mayoritariamente, al ámbito de las ciencias religiosas, pero, gracias a las múltiples donaciones, no se han descuidado otras ramas del saber. En la actualidad existen alrededor de 43.500 volúmenes y mantiene más de 50 suscripciones activas a revistas teológicas, filosóficas, pedagógicas, históricas y literarias, que superan otros 3000 volúmenes adicionales. Estos fondos proceden de compras, suscripciones a editoriales y donaciones de entidades culturales extremeñas y de particulares, destacando, muy especialmente, las del clero diocesano.

Los fondos se organizan en torno a una clasificación temática, diseñada a finales del siglo Xx. Las grandes materias son: A (arte), B (bibliografía), D (derecho civil), F (filosofía en sus diversos tratados, filosofía de la naturaleza, historia de las ciencias), FC (filología clásica: autores griegos y latinos), H (historia), L (literatura, lingüística y filología castellana, francesa, italiana, inglesa, alemana, etc.), $\mathrm{S}$ (sociología) y $\mathrm{T}$ (teología).

La Biblioteca cuenta en la actualidad con 7 libros de registros, especialmente importantes, pues muchos libros llegan a la biblioteca por donación. Por eso, además de los datos técnicos de la obra, se anota su procedencia. El análisis de los mismos nos permite conocer quiénes fueron, quiénes son y quiénes serán los grandes benefactores de nuestra biblioteca.

Con la signatura EN (ediciones notables) la biblioteca clasifica y custodia de manera especial libros, a los que también podrían clasificarse bajo la condición de «raros», como sucede en otras bibliotecas.

A esta clasificación remiten los ejemplares incunables (1484 a 1499) con los que nuestro centro cuenta:

Baptista de Salis. Summacasuumconscientiae. Rosellacasuum. Venetiis: GeorgiusArrivabene, 1495.

Benito, Santo. Regula. Compilatioregulae S. Benedicti. In Monasterio BMV de Monteserratto, 1499.

Biondo, Flavio. Historiarum ab inclinatione Romanorumimperiidecades. Venetiis: Thomas de Blavis, 1484.

Gerardus De Zutphania. De spiritualibusascensionibus. In Monasterio BMV de Monteserrato: Johannes Luschner, 1499. 
Nonio Marcelo. De proprietatelatinisermonis. Venetiis: Antonius de Gusago, 1498.

Prisciano Cesariense. Opera.Venetiis: BonetusLocatellus: impens. OctavianiScoti, 1496.

Pseudo Buenaventura. De instructionenovitiorum. De quattuo rvirtutibus cardinalibus. In Monasterio BMV de Monteserrato, 1499.

Pseudo Buenaventura. De triplicivia, siveIncendiumamoris, alias Fons vitae. In Monasterio BMV de Monteserrato, 1499.

Pseudo Buenaventura. Meditationes vitae Christi. In Monasterio BMV de Monteserrato, 1499.

La lista de estas obras no deja de crecer, conforme se avanza en un mejor conocimiento bibliográfico de nuestros fondos. Destaca la extraordinaria Políglota de Amberes o Biblia Regia de Arias Montano (1569). Hay otras Biblias interesantísimas del siglo XVI, particularmente las ilustradas, con múltiples grabados, que pueden ser considerados como verdaderas piezas de arte.

Hay una edición «princeps» romana de El Fisiólogo de San Epifanio (1587). Se trata de uno de los pocos ejemplares existentes en España. Hay también un ejemplar de los Sermones, de San Vicente Ferrer (1509), la Catena aurea, de Santo Tomás de Aquino (1520), las Obras, de Virgilio (1527), la edición italiana del Orlando Furioso, de Ariosto (1556), la edición de 1558 de la Gramática latina, de Nebrija, y, del mismo año, el Catecismo, del arzobispo de Toledo Bartolomé Carranza, uno de los poquísimos ejemplares existentes en el mundo, salvado de la destrucción a que fue sometida la edición.

La biblioteca es una entidad de titularidad privada, y como tal está específicamente dirigida a los seminaristas, sacerdotes de la diócesis de Mérida-Badajoz y profesores y alumnos del Centro Superior de Estudios Teológicos y del Instituto de Ciencias Religiosas Santa María de Guadalupe. Todos ellos tienen acceso a todos servicios prestados por la biblioteca: lectura en sala, reprografía y préstamo. Además, el Seminario, conocedor de la importancia de sus fondos para el desarrollo de la cultura, ofrece a todos los investigadores acceso a ellos través de su consulta en sala y de medios reprográficos.

En los últimos tiempos, la biblioteca del Seminario se viene esforzándose por ir dando a conocer al público, mediante diversas actuaciones, libros de importancia para la investigación sobre temas específicos. Se han organizado varias exposiciones. Destacaremos: la de Fondos Bibliográficos de Indias (1985), dedicadas a fondos americanistas; la Emblemática y sus fuentes (1987); las dedicadas a la literatura emblemática, Heráldica y otros grabados (1991), y la más actual, San Juan de Ribera (2011), sobre la figura de este obispo. 
Hay que sumar artículos en variadas revistas ${ }^{21}{ }^{21}$ libros $^{22}$ y otras actividades de difusión. ${ }^{23}$

La catalogación completa del patrimonio bibliográfico, la adquisición de nuevos fondos para ponerlos a disposición de la comunidad científica por medio de un sistema integral de gestión bibliotecaria son tres de los principales objetivos. Se está confeccionando un catálogo de todos los fondos bibliográficos desde su creación hasta el siglo XXI.

La Biblioteca del Seminario Metropolitano de San Atón pretende continuar siendo cada día más una herramienta eficaz de acceso a los ricos fondos de su patrimonio bibliográfico.

${ }^{21}$ Pérez Ortiz, M ${ }^{\text {a }}$ G. «La biblioteca del Seminario Metropolitano de San Atón de Badajoz: la mejor colección religiosa de Extremadura». Mi Biblioteca VIII: 105-112; Pérez Ortiz, Mª G. y Tejada Vizuete, F. «La Biblioteca del Seminario Metropolitano San Atón de Badajoz: un presente con mucha historia». Vitela X: 4-7; Vizuete, F. y Pérez Ortiz, Mª G. «La biblioteca del Seminario Metropolitano de San Atón. Libros del siglo XVI impresos en España, Lyon, París, Amberes, Italia, Alemania y Portugal», Pax et Emerita. Revista de Teología y Humanidades de la Archidiócesis de Mérida-Badajoz. III-VII.

${ }^{22}$ Solar y Taboada, A. 1945. El Seminario de San Atón de Badajoz: 85-89. Badajoz; Rubio Merino, P. 1964. El Seminario de San Atón de Badajoz (1664-1994). Madrid: Monte de Piedad y Caja Genera del Ahorros de Badajoz; Blanco Cotano, M. 1998. El primer centro universitario de Extremadura. Badajoz 1793. Historia pedagógica del Seminario de San Atón. Cáceres: Universidad de Extremadura.

${ }^{23}$ Conferencias y visitas a la biblioteca que tienen como finalidad el acercamiento de la misma a la sociedad y el mejor conocimiento y difusión de nuestros fondos. 